\title{
Desmosomal Plakophilins in the Prostate and Prostatic Adenocarcinomas
}

\section{Implications for Diagnosis and Tumor Progression}

\author{
Sonja Breuninger, ${ }^{*}$ Sonja Reidenbach, ${ }^{*}$ \\ Christian Georg Sauer, ${ }^{\dagger}$ Philipp Ströbel, ${ }^{\dagger}$ \\ Jesco Pfitzenmaier, ${ }^{\ddagger}$ Lutz Trojan, $\$$ \\ and Ilse Hofmann* \\ From the Joint Research Division Vascular Biology of the Medical \\ Faculty Mannheim, Heidelberg University, and the German Cancer \\ Research Center (DKFZ-ZMBH-Alliance)," Center for Biomedicine \\ and Medical Technology Mannheim (CBTM), Mannheim; Institute \\ of Pathology, ${ }^{\dagger}$ and Clinic for Urology, University Medical Center \\ Mannheim, Heidelberg University, Mannheim; and Department \\ of Urology, ${ }^{\ddagger}$ Medical Faculty Heidelberg, Heidelberg University, \\ Heidelberg, Germany
}

The plakophilins, members of the armadillo-repeat family, consist of three different proteins (PKP1-3) that are specifically recruited to desmosomal plaques in a highly cell type-specific manner. Using immunofluorescence, immunoelectron microscopy, and immunoblot, we found that all three plakophilins occurred in luminal and basal cells of the pseudostratified prostate epithelium. The analysis of $\mathbf{1 3 5}$ cases of prostatic adenocarcinomas grouped into tumors with low (Gleason score $\leq 6$ ), intermediate (Gleason score 7 ), and high Gleason score $(8 \leq$ Gleason score $\leq 10)$ showed that the expression of PKP1 was reduced or lost in adenocarcinomas with high Gleason scores. The expression of PKP2 was unchanged in all prostatic adenocarcinomas analyzed. In contrast, PKP3 expression was increased in carcinomas with high Gleason scores in comparison with carcinomas with low Gleason scores. In DU 145 cell lines with either overexpression or knockdown of PKP3, both imbalances resulted in fewer desmosomal cell contacts. In addition, overexpression of PKP3 in DU 145 cells led to an augmentation in proliferation rate. Our data imply that both loss of PKP1 and up-regulation of PKP3 expression are biologically important events in prostate cancer and are associated with a more aggressive phenotype. (Am J Pathol 2010, 176:2509-2519; DOI: 10.2353/ajpatb.2010.090737)
Cell-cell adhesion is particularly important for the formation and maintenance of normal tissue architecture. The human prostate epithelium is composed of luminal cells with secretory activity and basal cells forming a pseudostratified epithelium with dispersed neuroendocrine cells. Different types of junctions such as adherens junctions, desmosomes, and tight junctions mediate the contact between epithelial cells. ${ }^{1,2}$ Various transmembrane proteins are complexed with plaque proteins specific for each type of junction (eg, in desmosomes, the desmogleins and desmocollins act as $\mathrm{Ca}^{2+}$-dependent transmembrane glycoproteins, which at their cytoplasmic portion, are complexed with desmoplakin, plakoglobin, and plakophilins).

Several junctional plaque proteins belong to the armadillo (arm)-repeat protein family, characterized by tandem arrays of a 42-amino acid repeat motif. This family includes $\beta$-catenin, plakoglobin, and the members of the more closely related p120 subfamily, namely a subgroup localized to adherens junctions, consisting of the namegiving protein p120, Armadillo repeat gene deleted in velocardio-facial syndrome (ARVCF), protein p0071, neurojungin, and the desmosomal plakophilins. ${ }^{3,4}$ In addition to their junctional localization, most of these proteins also occur at varying degrees in the cyto- and nucleoplasm, and it has been suggested that this may reflect a dual function common to most arm-repeat proteins with key roles in both cell adhesion and signaling. ${ }^{5,6}$ For $\beta$-catenin and protein $\mathrm{p} 120$, cytoplasmic and nuclear binding partners have been identified and their implementation in signaling cascades (eg, the wnt signaling pathway) is well characterized. ${ }^{7}$

The plakophilins make up three different proteins (PKP1-3) that are specifically recruited to desmosomal

\footnotetext{
Supported by a project grant from the Deutsche Krebshilfe (107861) to I.H. Accepted for publication January 19, 2010

Supplemental material for this article can be found on http://ajp. amjpathol.org

Address reprint requests to Dr. Ilse Hofmann, Joint Research Division Vascular Biology of the Medical Faculty Mannheim, University of Heidelberg, and the German Cancer Research Center, CBTM, Ludolf-KrehlStrasse 13-17, 68167 Mannheim, Germany. E-mail: i.hofmann@dkfz.de.
} 
Table 1. Primary Antibodies Used

\begin{tabular}{|c|c|c|}
\hline Antigen & Antibody & Source \\
\hline \multicolumn{3}{|l|}{ Plakophilins } \\
\hline \multirow[t]{2}{*}{ PKP1 } & $m A b, m$ & $\begin{array}{l}\text { Clone PP1-5C2 (Progen } \\
\text { Biotechnik, Heidelberg, } \\
\text { Germany) }\end{array}$ \\
\hline & As, gp & $\begin{array}{l}\text { PP1 B6-4 (Progen } \\
\text { Biotechnik) }\end{array}$ \\
\hline \multirow[t]{3}{*}{ PKP2 } & mAb, m & $\begin{array}{c}\text { Clones PP2/62, PP2/86, PP2/ } \\
150 \text { (Progen Biotechnik) }\end{array}$ \\
\hline & As, gp & Head $a^{5}$ \\
\hline & $\begin{array}{l}\text { As, gp } \\
\text { As, gp }\end{array}$ & $\begin{array}{l}\mathrm{NIb}^{5} \\
\mathrm{HP} 1 \alpha^{5}\end{array}$ \\
\hline \multirow[t]{3}{*}{ PKP3 } & $m A b, m$ & $\begin{array}{l}\text { Clone PKP3-270.6.2 (Progen } \\
\text { Biotechnik) }\end{array}$ \\
\hline & mAb, m & $\begin{array}{l}\text { Clone 23E3/4 (Acris } \\
\text { Antibodies, Herford, } \\
\text { Germany) }\end{array}$ \\
\hline & $\begin{array}{l}\text { mAb, m } \\
\text { As, gp }\end{array}$ & $\begin{array}{l}\text { Biomol, Hamburg, Germany } \\
\text { PP3-1 (Progen Biotechnik) }\end{array}$ \\
\hline \multicolumn{3}{|l|}{$\begin{array}{l}\text { Desmosomal } \\
\text { proteins }\end{array}$} \\
\hline \multirow[t]{2}{*}{ Desmoplakin } & $m A b, m$ & $\begin{array}{l}\text { DP1\&2-2.15; DP1-2.17; } \\
\text { DP1\&2-2.20 (Progen } \\
\text { Biotechnik) }\end{array}$ \\
\hline & As, gp & DP no. $495^{22}$ \\
\hline Desmoglein 2 & As, rb & rb5 (Progen Biotechnik) \\
\hline Desmoglein 2 & As, rb & $\begin{array}{l}\text { rb8, (provided by L. } \\
\text { Langbein, German Cancer } \\
\text { Research Center, } \\
\text { Heidelberg, Germany) }\end{array}$ \\
\hline \multirow{3}{*}{$\begin{array}{c}\text { Desmoglein 1/2 } \\
\text { Plakoglobin } \\
\text { ( } \gamma \text {-catenin }) \\
\text { Arm-repeat } \\
\text { proteins of } \\
\text { adherens } \\
\text { junctions }\end{array}$} & $m A b, m$ & DG 3.10 (Progen Biotechnik) \\
\hline & $\begin{array}{l}\mathrm{mAb}, \mathrm{m} \\
\mathrm{mAb}, \mathrm{m}\end{array}$ & $\begin{array}{l}\text { Clone } 11 \mathrm{E} 4^{5} \\
\text { Invitrogen }\end{array}$ \\
\hline & & \\
\hline \multirow[t]{2}{*}{ Protein p120 } & mAb, m & $\begin{array}{c}\text { BD Biosciences Pharmingen, } \\
\text { Heidelberg, Germany }\end{array}$ \\
\hline & As, rb & $\begin{array}{l}\text { Sigma-Aldrich, Deisenhofen, } \\
\text { Germany }\end{array}$ \\
\hline \multirow[t]{3}{*}{ Protein p0071 } & $m A b, m$ & $\begin{array}{l}\text { Clone } 7.7 .9 \text { (Progen } \\
\text { Biotechnik) }\end{array}$ \\
\hline & mAb, m & $\begin{array}{l}\text { Clone 406.3.1 (Progen } \\
\text { Biotechnik) }\end{array}$ \\
\hline & As, gp & $\begin{array}{l}\text { hp0071 (Progen } \\
\text { Biotechnik) }\end{array}$ \\
\hline \multirow[t]{4}{*}{ ARVCF } & As, gp & $\begin{array}{l}2 \times \text { hARVCF (Progen } \\
\text { Biotechnik) }\end{array}$ \\
\hline & As, gp & $3 \times$ hARVCF $^{39}$ \\
\hline & $m A b, m$ & $\begin{array}{l}\text { Clone } 1056 \text { (Progen } \\
\text { Biotechnik) }\end{array}$ \\
\hline & mAb, m & Clone $978^{23}$ \\
\hline \multirow[t]{4}{*}{$\begin{array}{l}\text { Neurojungin } \\
\quad(\delta \text {-catenin })\end{array}$} & $m A b, m$ & $\begin{array}{l}\text { Clone J19 (Progen } \\
\text { Biotechnik) }\end{array}$ \\
\hline & $\mathrm{mAb}, \mathrm{m}$ & Clone $7 A^{24}$ \\
\hline & $\begin{array}{l}\text { mAb, m } \\
\text { As, rb }\end{array}$ & $\begin{array}{l}\text { BD Biosciences Pharmingen } \\
\text { KE20 (Sigma-Aldrich) }\end{array}$ \\
\hline & As, rb & YV19 (Sigma-Aldrich) \\
\hline$\beta$-Catenin & $\begin{array}{l}\text { mAb, m } \\
\text { As, rb }\end{array}$ & $\begin{array}{l}\text { BD Biosciences Pharmingen } \\
\text { Sigma-Aldrich }\end{array}$ \\
\hline \multicolumn{3}{|l|}{$\begin{array}{l}\text { Classical } \\
\text { cadherins }\end{array}$} \\
\hline E-Cadherin & $\begin{array}{l}\text { mAb, m } \\
\text { mAb, rb }\end{array}$ & $\begin{array}{l}\text { BD Biosciences Pharmingen } \\
\text { Biomol }\end{array}$ \\
\hline N-Cadherin & $m A b, m$ & A-CAM (Sigma-Aldrich) \\
\hline & $\mathrm{mAb}, \mathrm{m}$ & $\begin{array}{l}\text { Clone 32, BD Biosciences } \\
\text { Pharmingen } \\
\text { (table continues) }\end{array}$ \\
\hline
\end{tabular}

Table 1. Continued

\begin{tabular}{|c|c|c|}
\hline Antigen & Antibody & Source \\
\hline \multicolumn{3}{|l|}{ Marker proteins } \\
\hline Keratin 5 & As, gp & GP5.2 (Progen Biotechnik) \\
\hline Keratin 8 & As, gp & K8.2 (Progen Biotechnik) \\
\hline Keratin $8+18$ & As, gp & K8/K18 (Progen Biotechnik) \\
\hline \multirow[t]{2}{*}{ Keratin 14} & $m A b, m$ & $\begin{array}{l}\text { LL002 (Natutec, Frankfurt, } \\
\text { Germany) }\end{array}$ \\
\hline & As, gp & $\begin{array}{l}\text { GP CK } 14.2 \text { (Progen } \\
\text { Biotechnik) }\end{array}$ \\
\hline Keratin 18 & As, gp & $\begin{array}{l}\text { GP CK18.2 (Progen } \\
\text { Biotechnik) }\end{array}$ \\
\hline \multicolumn{3}{|l|}{ Others } \\
\hline$\alpha$-Catenin & $\begin{array}{l}m A b, m \\
\text { As, rb }\end{array}$ & $\begin{array}{l}\text { Invitrogen } \\
\text { Sigma-Aldrich }\end{array}$ \\
\hline$\beta$-Actin & $m A b, m$ & $\begin{array}{l}\text { Novus Biological, Acris } \\
\text { Antibodies }\end{array}$ \\
\hline myc-tag & $\mathrm{Rb}$ & $\begin{array}{l}\text { ab9106 (Abcam, } \\
\text { Cambridge, UK) }\end{array}$ \\
\hline
\end{tabular}

mAb, monoclonal antibody; As, conventionally prepared antiserum; rb, rabbit; $m$, mouse; gp, guinea pig.

plaques in a highly cell type-specific manner. Protein p0071, also called PKP4, is more closely related to other members of the p120 subfamily and is localized as a nondesmosomal plaque protein in adherens junctions. ${ }^{8,9}$ Only PKP2 has been detected in all desmosome-producing cell types, including simple and stratified epithelia as well as nonepithelial tissues such as myocardium and lymph node follicles. ${ }^{5,10}$ In contrast, PKP1 is restricted to stratified and complex epithelia and urothelium, ${ }^{11}$ whereas PKP3 is located in almost all desmosome-bearing cells, with the exception of desmosomes between hepatocytes and between cardiomyocytes. ${ }^{12,13}$

Prostate cancer is the most frequent malignancy in men of the western civilization and early detection is essential to reduce mortality and increase survival. In recent years, evidence has been accumulated that several junctional proteins play important roles in carcinogenesis, tumor invasion and metastasis. As a prototypic example, $\beta$-catenin mutations in colorectal carcinomas result in impaired $\beta$-catenin degradation ${ }^{14}$ with profound effects on downstream signaling pathways. Loss, downregulation, or mislocalization of another important junctional protein, protein $\mathrm{p} 120$, has been found to correlate with tumor progression. ${ }^{15}$ In contrast, the potential role of plakophilins in human tumorigenesis and progression is largely unexplored. A few immunohistochemical studies on squamous cell carcinoma suggested a correlation with clinical parameters ${ }^{16-18}$ and point to a potentially important role.

In the past, the occurrence of PKPs in normal prostate epithelium and in prostatic adenocarcinoma has not been analyzed. Therefore, we performed immunofluorescence and immunoelectron microscopy to study the distribution of PKP1-3 in human prostate. All three PKPs were detectable in normal luminal and basal cells of glandular prostatic epithelium. The analysis of adenocarcinomas of the prostate together with observations in prostatic cell lines with either overexpression or knockdown of PKPs implies that loss of PKP1 and up-regulation of PKP3 expression are biologically important events in prostate cancer. 


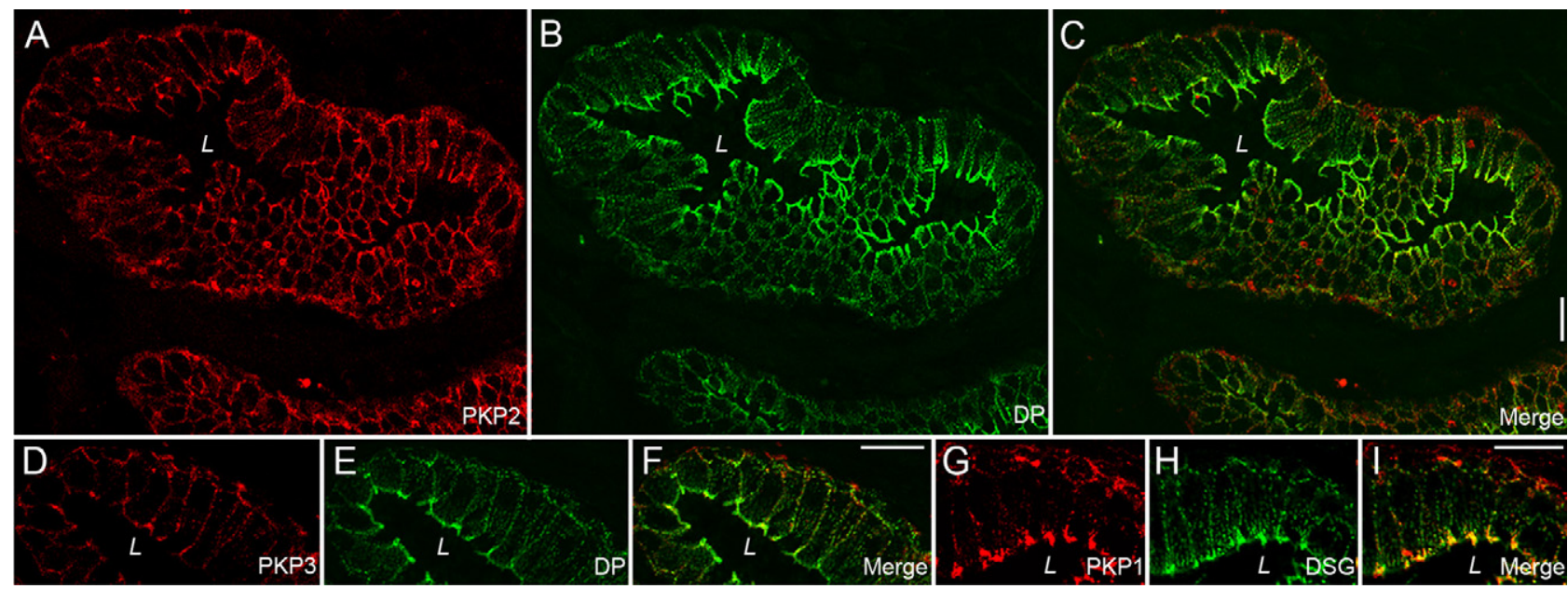

Figure 1. Immunofluorescence results of double-labeling experiments on cryostat sections throughout the human prostate. The localization of plakophilins PKP1-3 (A red, PKP2; D, red, PKP3; and G, red, PKP1) is compared with that of desmoplakin (B and $\mathbf{E}$, green, DP) or desmoglein (H, green, DSG). The corresponding merged pictures are also shown $(\mathbf{C}, \mathbf{F}$, and $\mathbf{I}$ ). Note the punctate staining and the pronounced localization at the apical portion of the basolateral membranes typical for desmosomes in polar epithelia. In higher magnifications $(\mathbf{D}-\mathbf{I})$, basal cells occur also positive for plakophilins. Abbreviation: $L$, lumen. Scale bars $=20 \mu \mathrm{m}$.

\section{Materials and Methods}

\section{Cultured Cells and Tissues}

Cell cultures derived from prostatic hyperplasia and metastases used in this study were the benign cell line $\mathrm{BPH}-1^{19}$ and the malignant cell lines DU 145 and LNCaP (for further information on cell lines, see the catalog of the American Tissue Culture Collection, Manassas, VA). The $\mathrm{BPH}-1$ cell line was cultivated in RPMI 1640 medium (Invitrogen, Karlsruhe, Germany) with 1\% glutamine (In- vitrogen), 10\% fetal bovine serum (Biochrom, Berlin, Germany), $1 \mu \mathrm{g} / \mathrm{ml}$ insulin (Sanofi-Aventis, Frankfurt, Germany), $20 \mathrm{ng} / \mathrm{ml}$ testosterone (Sigma-Aldrich, Steinheim, Germany), $5 \mu \mathrm{g} / \mathrm{ml}$ transferrin (Sigma-Aldrich), and 10 $\mathrm{ng} / \mathrm{ml}$ hydrocortisone (Fluka, Steinheim, Germany). The cell lines DU 145 and LNCaP were cultivated in RPMI 1640 medium with 10\% fetal bovine serum and 1\% glutamine. Tumor-free human prostatic tissue samples were obtained from tumor prostatectomies at the Department of Urology, Medical Faculty Heidelberg and Medical Fac-

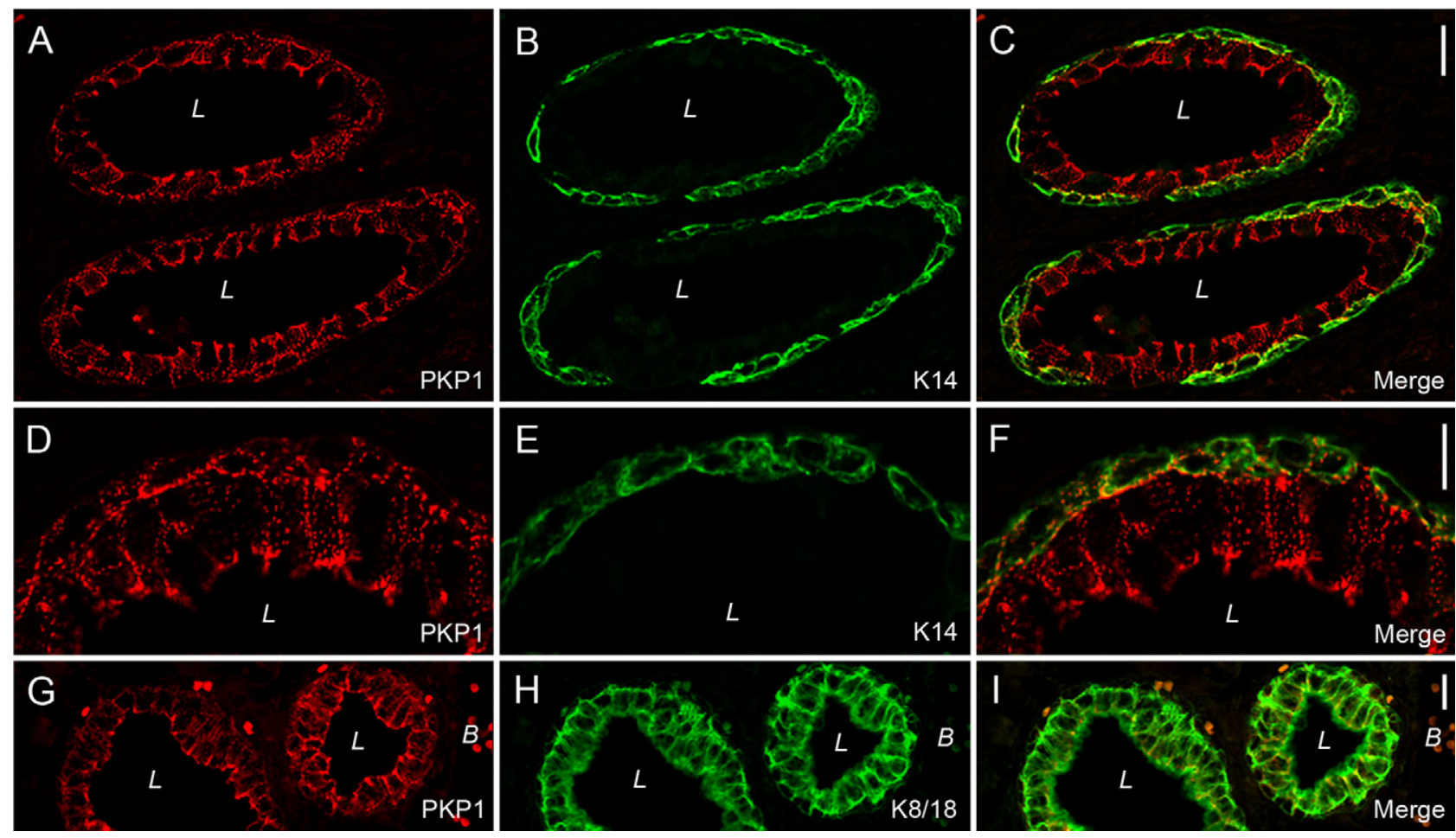

Figure 2. Detection of PKP1 on formaldehyde-fixed, paraffin-embedded tissues of tumor-free human prostate (A, D, and G) compared with the localization of keratin 14 (B and $\mathbf{E}$, K14) and keratin 8 and keratin 18 (H, K8/18). In D-F, a higher magnification of the glandular epithelium is shown. The merged pictures are given in $(\mathbf{C}$ $\mathbf{F}$, and $\mathbf{I})$. Note PKP1 is detectable in both types of cells, luminal and basal cells. Abbreviations: $L$, lumen; $B$, blood vessel. Scale bars: $20 \mu \mathrm{m}(\mathbf{C}$ and $\mathbf{I}) ; 10 \mu \mathrm{m}(\mathbf{F})$. 
ulty Mannheim, Heidelberg University (Heidelberg, Germany), with the permission of the ethics committee of the Medical Faculty. Formaldehyde-fixed, paraffin-embedded prostatic adenocarcinomas were provided from the National Center for Tumor Diseases (Heidelberg, Germany) and the Department of Pathology, Medical Faculty Mannheim, Heidelberg University.

\section{Patients}

A total of 135 tissue samples were analyzed: 44 cases with low Gleason scores of 3 to 6,38 cases with an intermediate Gleason score of 7, and 53 cases with high Gleason scores of 8 to $10 .^{20}$ The patients' age was between 52 and 77 years, and their prostate-specific antigen blood levels ranged between 0.5 and $97.6 \mathrm{ng} / \mathrm{ml}$. A total of 71 tissue samples were investigated by paraffin multitissue arrays that consisted of five representative punches of tumor and three nonneoplastic prostate tissues per case (for technical details, see Ref. 21). With both, full-sized and microarray samples comparable results were obtained.

\section{Antibodies}

The primary antibodies used in this study are listed in Table 1. ${ }^{5,6,8,9,11,13,22-24,39}$ Details on references and distributors can also be found in Table 1.5,6,8,9,11,13,22-24,39 Secondary antibodies used for immunofluorescence microscopy were species-specific goat antibodies against Igs of guinea pig, mouse, or rabbit conjugated to Cy3 (BioTrend, Cologne, Germany) or Alexa 488 (MoBiTec, Göttingen, Germany). For immunoblot analysis, horseradish peroxidase-conjugated secondary antibodies

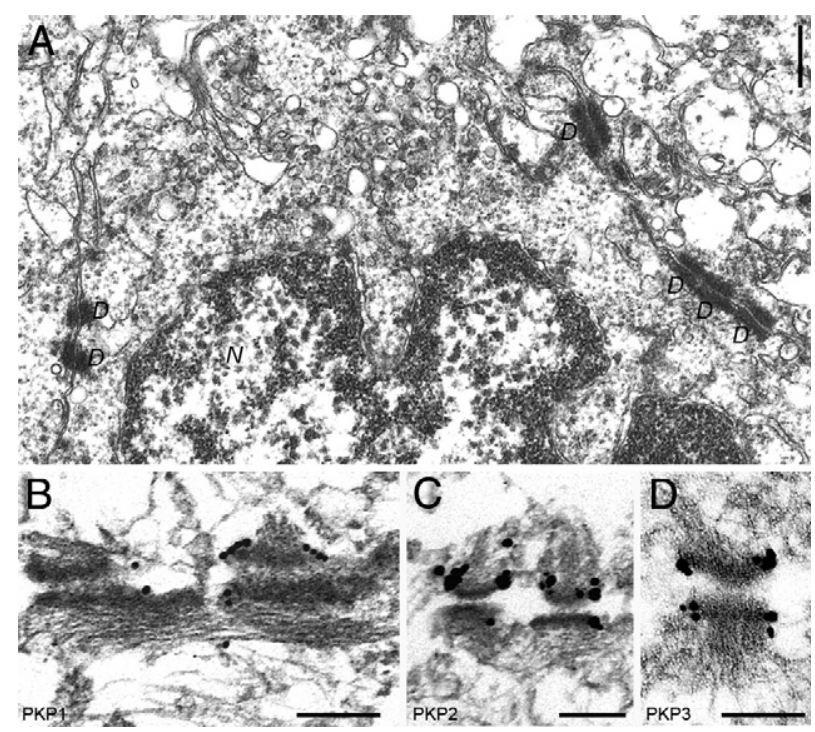

Figure 3. Conventional electronmicroscopy of glandular epithelial cells of human prostate (A) and immunoelectron microscopic localization of plakophilins (immunogold reactions, followed by silver enhancement) to desmosomes using antibodies specific for PKP1 (B), PKP2 (C), or PKP3 (D). Note the prominent decoration of the electrodense cytoplasmic plaques of desmosomes with all three antibodies specific for PKP1-3. Abbreviations: $D$, desmosome; $N$, nucleus. Scale bars: $500 \mathrm{~nm}(\mathbf{A}) ; 200 \mathrm{~nm}(\mathbf{B}-\mathbf{D})$. were applied in combination with the enhanced chemiluminescence system (AceGlow-Solution; PEQLAB Biotechnologie, Erlangen, Germany).

\section{Immunofluorescence Microscopy and Immunoelectron Microscopy}

The methods used for single- and double-label antibody immunofluorescence microscopy on sections of frozen tissues and cultured cells were described in detail elsewhere. ${ }^{8}$ For sectioning of paraffin-embedded tissues (3 to $5 \mu \mathrm{m}$ ), a microtome (HM 430; Microm, Walldorf, Germany) was used. Briefly, sections were deparaffinized according to standard techniques and thereafter pretreated to retrieve masked antigens $(0.05 \mathrm{M}$ Tris- $\mathrm{HCl}$ buffer, $\mathrm{pH} 10.2,12$ minutes, $120^{\circ} \mathrm{C}$ for detection of PKP1, PKP2, and ARVCF and 0.1 M Tris buffer containing 10\% urea, $\mathrm{pH} 11,15$ minutes, $120^{\circ} \mathrm{C}$ for detection of PKP3, protein $\mathrm{p} 0071$, and protein $\mathrm{p} 120$ ) with a multifunctional microwave processor (RHS-1; Milestone, Sorisole, Italy). Alternatively, the samples were heated in their appropriate buffer either with a standard microwave (Panasonic, Hamburg, Germany) at 600 W or a steamer (Braun, Kronberg, Germany) for 25 minutes. Sections were then treated with $0.2 \%$ Triton X-100 in PBS for 5 minutes, washed with PBS (twice 5 minutes), blocked with $5 \%$ goat serum and 2\% milk powder in PBS (10 minutes), and then processed for immunofluorescence microscopy. For PKP1 and PKP2 staining sections were additionally incu-

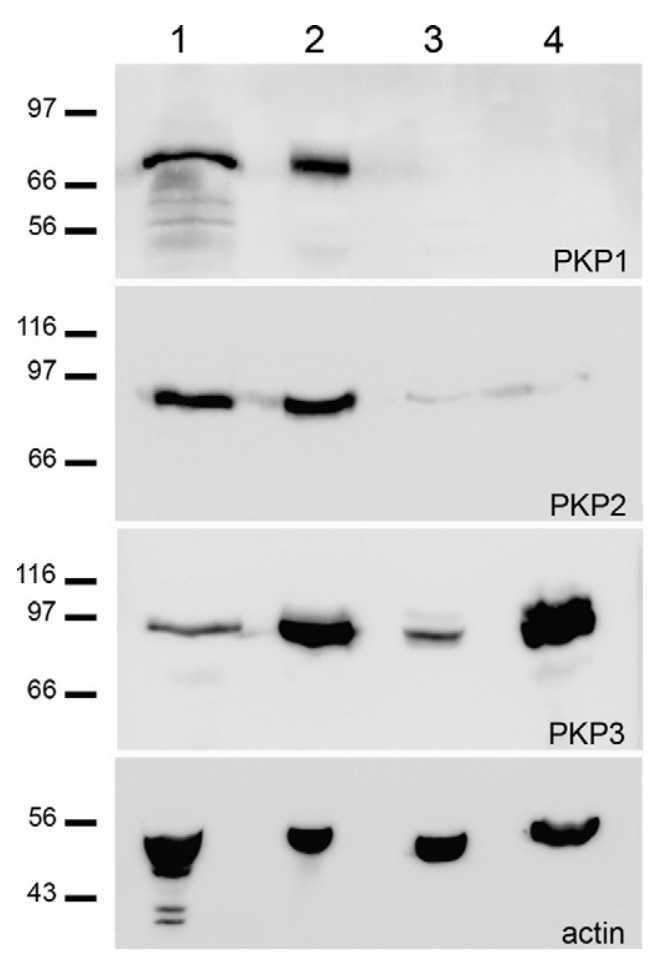

Figure 4. Immunoblot identification of plakophilins PKP1-3 in various cultured prostatic cell lines and human prostate tissue. The reactions are shown from following total lysates: human prostate (lane 1), BPH-1 (lane 2), DU 145 (lane 3), and LNCaP (lane 4). As a loading control, an immunoblot for $\beta$-actin (actin) was performed. Molecular weight markers are as indicated in kilodaltons in the left margin. 
Table 2. Immunofluorescence Results for the Plakophilins, PKP1-3 in Low, Intermediate, And High Gleason Scores of Prostatic Adenocarcinoma

\begin{tabular}{lcccc}
\hline & \multicolumn{3}{c}{ Tissue samples } \\
\cline { 2 - 5 } & \multicolumn{1}{c}{ Total } & Low Gleason score & Intermediate Gleason score & High Gleason score \\
\hline PKP1 & $55 / 135(41 \%)$ & $33 / 44(75 \%)$ & $10 / 38(26 \%)$ & $12 / 53(23 \%)$ \\
Positive & $68 / 135(50 \%)$ & $5 / 44(11 \%)$ & $26 / 38(69 \%)$ & $37 / 53(70 \%)$ \\
Inhomogeneous & $12 / 135(9 \%)$ & $6 / 44(14 \%)$ & $2 / 38(5 \%)$ & $4 / 53(7 \%)$ \\
Negative & $106 / 132(80 \%)$ & $34 / 41(83 \%)$ & $32 / 38(84 \%)$ & $40 / 53(75 \%)$ \\
PKP2 & $26 / 132(20 \%)$ & $7 / 41(17 \%)$ & $6 / 38(16 \%)$ & $13 / 53(25 \%)$ \\
Positive & & $26 / 41(63 \%)$ & $35 / 38(92 \%)$ & $47 / 53(89 \%)$ \\
Negative & $108 / 132(82 \%)$ & $3 / 38(8 \%)$ & $6 / 53(11 \%)$ \\
PKP3 & $24 / 132(18 \%)$ & $15 / 41(37 \%)$ & & \\
Positive & & & & \\
Negative & & &
\end{tabular}

bated before blocking with $2 \mu \mathrm{g} / \mathrm{ml}$ proteinase K (DakoCytomation, Hamburg, Germany) for 8 minutes at $37^{\circ} \mathrm{C}$, followed by 8 minutes at room temperature. The PKP1-3specific antibodies were incubated for 4 hours at room temperature (PKP1 and PKP2) or overnight at $4^{\circ} \mathrm{C}$ (PKP3), the secondary antibodies for 1 hour. As control for unspecific binding, incubation with primary antibody was omitted, and the specimens were incubated with secondary antibody only. Micrographs were taken with an Axiophot microscope (Zeiss, Jena, Germany). Confocal laser scanning immunofluorescence microscopy was done on a Zeiss LSM 510 UV instrument (Zeiss) as described before. ${ }^{25}$ Procedures used for conventional electron microscopy and immunoelectron microscopy were as described in detail elsewhere. ${ }^{26}$

\section{Interpretation of Immunfluorescence Signal}

A representative section of each tumor sample was stained with H\&E to verify tumor classification and to proof the quality of the tissue sample by light microscopy. The extent of immunofluorescence signal was subclassified as homogeneous (staining of the whole tumor) or inhomogeneous (staining only in defined tumor areas). Immunofluorescence experiments were conducted with a negative control for each tumor sample by omitting primary antibody. In addition, an internal control representing nonneoplastic prostate tissue was included. Depending on the percentage of positive cells, the immune reactions were scored into negative $(<5 \%$ positive staining), inhomogeneous ( $5 \% \leq$ positive staining $\leq 90 \%$ ), and positive (>90\% positive staining). Immunofluorescence evaluation was performed and photographs were taken with an Axiophot microscope (Zeiss).

\section{Statistical Analyses}

Statistical differences between categoric variables were determined using Yates corrected $\chi^{2}$ test. Correlations between parameters in ordinal scales were analyzed by Spearman rank R test, as provided by the SPSS software (version 2000; SPSS, Chicago, IL). For all analyses, a value of $P<0.05$ was considered significant, unless otherwise stated.

\section{Gel Electrophoresis and Immunoblotting}

Lysates were generated by the addition of Laemmli sample buffer substituted with Benzonase (Merck, Darmstadt, Germany) to cells or tissues. For immunoblot, proteins decorated with specific primary and secondary antibodies were detected by applying the enhanced chemiluminescence system to the membranes. Light emission was recorded by a photomultiplier in a gel documentation system (ChemiSmart 5000; PEQLAB Biotechnologie).

\section{RNA Isolation and Real-Time PCR}

RNA from cells was isolated using a RNA isolation kit (RNAeasy; Qiagen, Hilden, Germany). Afterward, a RT-PCR was performed to transcribe RNA into CDNA (High Capacity cDNA Reverse Transcription kit; Applied Biosystems, Darmstadt, Germany). The obtained cDNA was diluted 1/5 for real-time PCR and added to the Power SYBR Green PCR

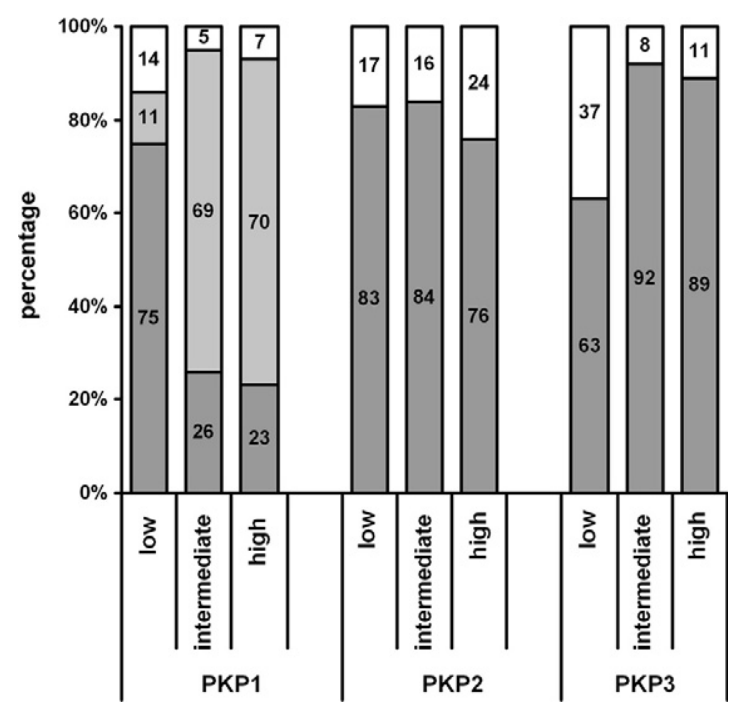

Figure 5. Occurrence of plakophilins (PKP1, PKP2, and PKP3) in prostatic adenocarcinoma in correlation with Gleason scores (low: Gleason score 3 to 6; intermediate: Gleason score 7; high: Gleason score 8 to 10). The percentages of negative (white color), inhomogeneous (light gray color), and positive (dark gray color) cases are given. 
Master Mix (Applied Biosystems). Primers against PKP1 (sequence forward: 5'-GACCAGGACAACTCCACGTT-3', reverse: 5'-CTGCTGGTGGTCCCATAGTT-3'), PKP2 (sequence forward: 5'-GCAAATGGTTGCTCGATाT-3', reverse: 5'-GGCTGGTAATCTGCAATGGT-3'), and PKP3 (sequence forward: 5'-TGATGAGCTTCGCAAAAATG-3', reverse: 5'-CTGAGAGGCTGAGCTGAGGT-3') were used, and the occurrence of corresponding DNA fragments was analyzed via StepOnePlus Real-Time PCR System (Applied Biosystems) and controlled by electrophoresis in $1 \%$ agarose gels. Hypoxanthine-guanine phosphoribosyltransferase RNA levels were used as internal reference to evaluate RNA recovery and to exclude variations between the different cell clones.

\section{Generation of cDNA Constructs, Transfections,} and Generation of Stable Cell Lines

The PKP3-pEGFP-N1 construct ${ }^{27}$ was cloned into the pLenti6.2/V5-DEST plasmid (Invitrogen) via the pENTR3C plasmid using restriction sites EcoRI and EcoRV, followed by Clonase reaction as specified by the manufacturer. As a negative control a pLenti-IRES-EGFP plasmid containing enhanced green fluorescent protein (EGFP) only was used (provided by A. Fischer, CBTM). Additionally, a PKP3-myc tag construct was created by replacing the EGFP tag with annealed oligonucleotides coding for the myc tag (5'-CGGAGCAGAAACTCATCTCAGAAGAGGATCTGTGGT-3' and 5'-CTAGATTACAGATCCTCTTCTGAGATGAGTTCTGCTCCGGTAC-3') in the PKP3-pEGFP-N1 vector.

To generate PKP3-specific short hairpin (sh)RNAs, oligonucleotides against different PKP3-mRNA targeting sites were synthesized (shPKP3-9: 5'-GTACCTCGGGACAGGACGTGAAGATAGTTCAAGAGACTATCTTCACGTCCTGTCCCTTTTTGGAAA-3' and 5'-AGCTTTTCCAAAAAGGGACAGGACGTGAAGATAGTCTCTTGAACTATCTTCACGTCCTGTCCCGAG-3'; shPKP3-1350: 5'-GTACCTCGGATCCTGTGGAACCTTTCATTCAAGAGATGAAAGGTTCCACAGGATCCTTTTTGGA-3'; and 5'-AGCTTTTCCAAAAAGGATCCTGTGGAACCTTTCATCTCTTGAATGAAAGGTTCCACAGGATCC-3').

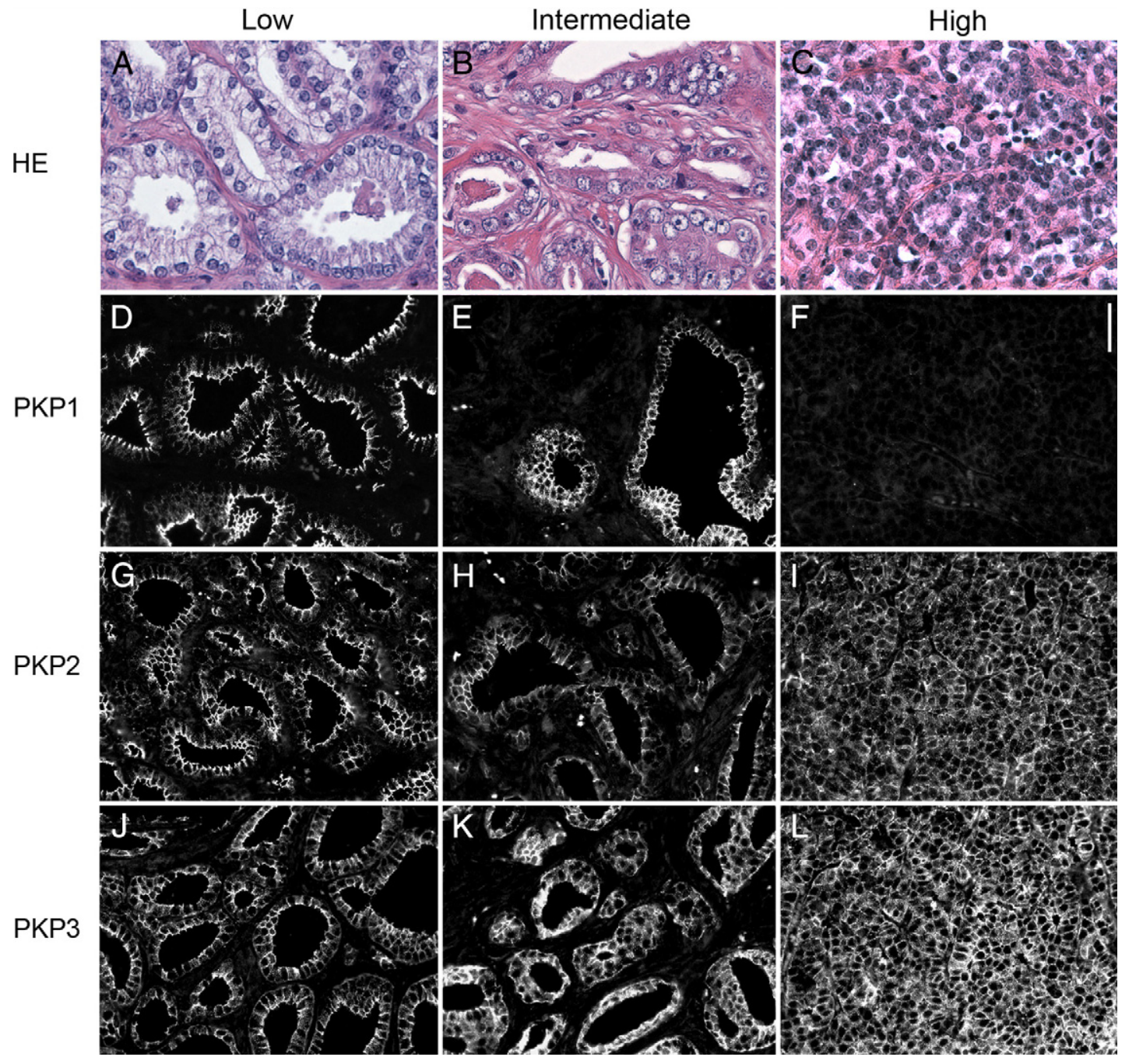

Figure 6. Detection of plakophilins on formaldehyde-fixed, paraffin-embedded tissue of prostatic adenocarcinoma grouped in low (A, D, G, and $\mathbf{J}$ ), intermediate $(\mathbf{B}, \mathbf{E}, \mathbf{H}$, and $\mathbf{K})$, and high $(\mathbf{C}, \mathbf{F}, \mathbf{I}$, and $\mathbf{L})$ Gleason score by immunofluorescence. H\&E is shown for a representative example of low (A, Gleason score 3 to 6 ), intermediate (B, Gleason score 7), and high (C, Gleason score 8 to 10) Gleason score. Immunolocalizations of PKP1 (D-F), PKP2 (G-I), and PKP3 (J-L) are presented. Note the heterogeneous detection of PKP1 in intermediate Gleason score and the loss of PKP1 in high Gleason score. Scale bars $=50 \mu \mathrm{m}$. 
The annealed oligonucleotides were ligated directly into the psiRNA-h7SKZeo plasmid (InvivoGen, Toulouse, France) using the unique Acc65I and HindlII restriction sites. As a negative control, a shRNA construct against Luciferase, shLuc, was used (InvivoGen).

The pLenti-PKP3-EGFP plasmid and the pLenti-EGFP plasmid were stably transduced into DU 145 cells according to the protocol of the manufacturer (Invitrogen), and cells were selected with $10 \mu \mathrm{g} / \mathrm{ml}$ blasticidin (Invitrogen). For generation of stable PKP3 knockdown cell clones and of the negative control cell clone, shLuciferase, DU 145 cells were transfected with the corresponding shRNA plasmids using Fugene 6 transfection reagent (Roche, Mannheim, Germany), followed by selection with $100 \mu \mathrm{g} / \mathrm{ml}$ Zeocin (Invitrogen). For selection of plasmid containing cell clones, the expression of EGFP was analyzed. A transient transfection with the PKP3-myc construct was also performed with Fugene 6 transfection reagent.

\section{Proliferation Assay}

DU 145 wild-type, PKP3 knockdown (shPKP3-1350), and PKP3 overexpressing (PKP3-EGFP) cells were seeded in a 96-well plate $\left(6 \times 10^{2}\right.$ cells/well). 5-Bromo-2'-deoxyuridine (BrdU) was added 48 hours later. Incorporation of BrdU was determined after another 24 hours, according to the protocol of the manufacturer (Cell Proliferation ELISA, BrdU (colorimetric); Roche). Absorbance at $400 \mathrm{~nm}$ (reference wavelength, $492 \mathrm{~nm}$ ) was measured using an ELISA reader (Tecan, Crailsheim, Germany). Statistical differences in proliferation between cell culture lines were analyzed using Student's $t$-test for unpaired experiments.

\section{Results}

\section{The Presence of Plakophilins in Normal Prostate}

To characterize the occurrence of arm-repeat proteins of the 120 subfamily in normal prostate, we systematically screened human tumor-free prostate by immunofluorescence on cryosections using antibodies specific for protein p120, ARVCF, protein p0071, neurojungin, and plakophilins 1-3. Thereby, we noticed a strong staining of the glandular epithelium for all members of the p120 subfamily with the exception of neurojungin (data not shown). According to previous reports, $2,5,11,13$ the occurrence of all three plakophilins in the glandular epithelium of the prostate, especially of PKP1, was unexpected, and therefore, we followed this observation in more detail. We compared the localization PKP1-3 with that of other desmosomal plaque proteins (eg, desmoplakin) and desmosomal transmembrane proteins (eg, desmoglein) and found for all three plakophilins colocalization with desmosomal marker proteins (Figure 1). All proteins showed a punctuate staining at cell borders and a pronounced accumulation at the apical portion of basolateral membranes typical for polar epithelia. The glandular epithelium of the prostate consists of luminal cells revealing secretory activity and stretched basal cells. By careful inspection at higher magnification, the basal cells were seen to be labeled by antibodies specific for PKP1-3. To unequivocally clarify if all three plakophilins occur in basal cells, we used antibodies specific for keratin 14, a marker for basal cells, and keratin 8 and keratin 18, markers for luminal and basal cells, ${ }^{28}$ and compared the localization with that of PKP1-3. To obtain better structural preservation, we used immunofluorescence on formaldehyde-fixed and paraffin-embedded tumor-free human prostate samples. Indeed, antibodies against all three plakophilins convincingly showed a decoration of both basal and luminal cells (Figure 2 and Supplemental Figure 1, see http://ajp.amjpathol.org). We also applied immunoelectron microscopy to verify the observation that all three plakophilins occur in the glandular epithelium of the prostate at the ultrastructural level (Figure 3). Antibodies against all three plakophilins decorated desmosomal plaques of neighboring epithelial cells in the glandular epithelium of prostate showing the typical appearance of desmosomes with a cytoplasmic electrodense plaque where intermediate filaments are inserted.

\section{The Detection of Plakophilins in Cultured Cells Derived from Prostatic Tissue}

We compared our results obtained on human prostatic normal tissue with cultured cells derived from human prostate. Cell cultures derived from prostatic hyperplasia (eg, BHP-1 cells) and metastases (eg, LNCaP cells isolated from lymph node metastases and DU 145 cells derived from a brain metastasis) were used, and immunoblotting using antibodies specific for the plakophilins, PKP1-3, was performed. Although all three plakophilins were detectable in lysates from prostatic tissue and from the benign cell line (BPH-1), only PKP3 showed a prominent reaction in lysates from both malignant cell lines, LNCaP and DU 145 (Figure 4). In contrast, PKP2 was
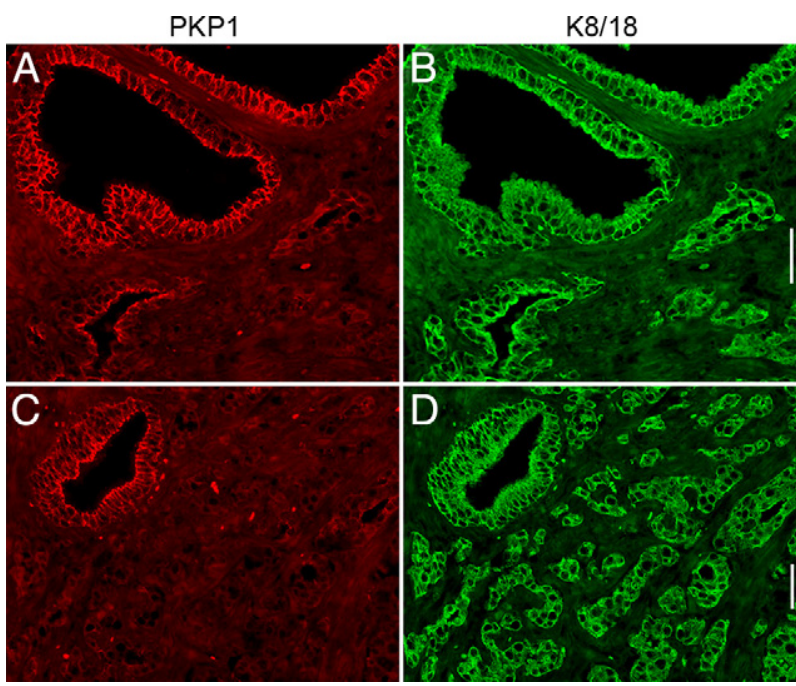

Figure 7. Detection of PKP1 on formaldehyde-fixed, paraffin-embedded tissue of an adenocarcinoma of the human prostate (A and C, PKP1) compared with the localization of keratin 8 and keratin 18 (B and $\mathbf{D}, \mathrm{K} 8 / \mathrm{K} 18$ ) Note the loss of PKP1 localization in adenocarcinoma of the prostate with high Gleason pattern. Scale bars $=50 \mu \mathrm{m}$ 
barely traceable in LNCaP and DU 145 cells, and PKP1 was not detectable in these cell lines. We verified these observations by immunofluorescence microscopy and found that PKP3 and PKP2 were detectable in desmosomes in all cell lines, whereas PKP1 was only observed in the benign cell line $\mathrm{BPH}-1$ (data not shown). Moreover, we performed RT-PCR on DU 145 cells and found mRNA expression of PKP3 (Supplemental Figure 2, see http:// ajp.amjpathol.org) and PKP2 but not of PKP1 (data not shown).

\section{The Plakophilins in Adenocarcinomas of the Prostate}

Because not all three plakophilins were detectable in malignant prostatic cell lines, we wondered whether the loss of plakophilins correlates with different tumor characteristics. Therefore, we systematically analyzed 135 prostatic adenocarcinomas with different Gleason scores
( $n=44$ with a low Gleason score between 3 and $6 ; n=$ 38 with an intermediate Gleason score 7 ; and $n=53$ with a high Gleason score 8 to 10) for expression of PKP1-3 by immunofluorescence. The findings are summarized in Table 2 and Figure 5. In summary, PKP1 expression was found less frequently and was generally lower in tumors with intermediate and high Gleason scores than in tumors with low Gleason scores, which was statistically highly significant $(P=0.00006)$. In contrast, PKP3 expression was significantly more frequent and generally higher in adenocarcinomas with intermediate or high Gleason scores than in tumors with low Gleason scores, of which $37 \%$ were completely negative $(P=0.0002)$. No major differences between the single groups were noted with regard to PKP2. There was no statistical correlation between PKP expression and prostate-specific antigen values (data not shown).

Representative immunofluorescence images for the presence of plakophilins in adenocarcinoma with low,
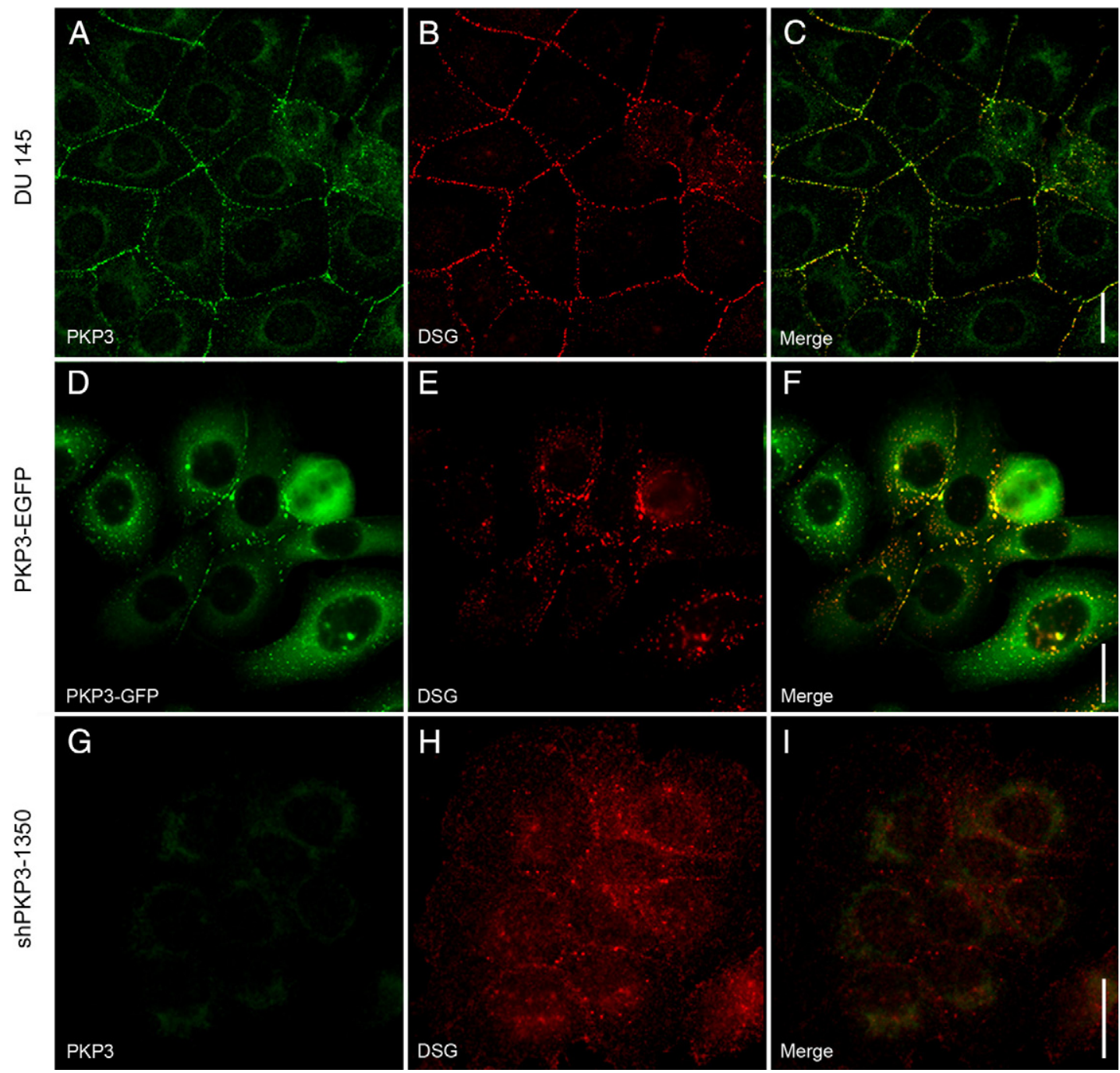

Figure 8. Influence of overexpression (D-F, PKP3-EGFP) or knockdown (G-I, shPKP3-1350) of PKP3 on DU 145-cultured cells compared with untreated cells (A-C, DU 145). The localization of endogenous PKP3 (A and G, PKP3) using monoclonal antibody clone PKP3-270.6.2 or exogenous PKP3 (D, PKP3-EGFP) is compared with the desmosomal marker desmoglein (B, E, and $\mathbf{H}$, DSG), using desmoglein-specific antibody rb5. The corresponding merged pictures are shown in $\mathbf{C}, \mathbf{F}$, and $\mathbf{I}$. Diffuse cytoplamics staining in $\mathbf{G}$ arises from the exogenous EGFP expression introduced with the shPKP3-1350 cDNA construct. Note an imbalance of PKP3 expression in DU 145 cells results in fewer desmosomes. Scale bars $=20 \mu \mathrm{m}$. 
intermediate, and high Gleason score are presented in Figure 6. In tumors with a low Gleason score, PKP1 and PKP2 were localized between neighboring cells, and PKP3 was additionally noticed in the cytoplasm of glandular epithelial cells. In tumors with intermediate Gleason scores, PKP1 occurred only in larger, more regular shaped glands, whereas in smaller glands with a tendency of the epithelial cells to spread in the surrounding stroma, the PKP1 signal was lost, whereas PKP2 and PKP3 were still detectable. This observation was even more prominent in carcinomas with a high Gleason score: colocalization of PKP1 with keratin 8/18, as an epithelial cell marker, revealed large tumor areas negative for PKP1 (Figure 7).

\section{Effects of PKP3 Overexpression and Knockdown on DU 145 Cells}

To analyze the potential functional consequences of overexpression of PKP3 in more aggressive tumors, we generated stable cell lines with modified expression of PKP3. We used the malignant cell line DU 145 and introduced cDNA constructs yielding either the overexpression of the fusion protein PKP3-EGFP ("gain of function") or reduced expression ("loss of function") through a shRNA interference approach. To knock down the expression of PKP3, two different target sequences were chosen yielding the cell clones shPKP3-9 and shPKP31350 with different RNA and protein levels of PKP3 (Supplemental Figure 2, see http://ajp.amjpathol.org). In contrast, a cell clone stably expressing shRNA specific for luciferase showed RNA and protein levels comparable with untreated DU 145 cells. The cell clone, shPKP3-1350, with the higher knockdown efficiency was used for further analyses. When PKP3-EGFP was expressed in DU 145 cells, this protein was detected at cell-cell contacts in desmosomes as shown by colocalization with desmosomal proteins (eg, desmoglein) but also in a decent amount in the cytoplasm (Figure 8). In addition, a high portion of uncoupled cells was observed in stably transfected cells where the portion of cytoplasmic PKP3-EGFP was even higher. As a control, a PKP3-myc construct was introduced in DU 145 cells, and here, PKP3 fused to a smaller tag also occurred in desmosomes and in the cytoplasm (Supplemental Figure 3, see http://ajp.amjpathol.org). In cell lines with knockdown of PKP3, the distribution of desmosomal proteins (eg, desmoglein) was also disturbed (Figure 8). Desmoglein was only rarely detectable in desmosomes and instead mostly localized in the cytoplasm in different sized structures. Taken together, our findings clearly showed that overexpression and knockdown of PKP3 interfered with the formation of desmosomes and thus with cell-cell contacts.

To further characterize the three cell lines with different PKP3 expression levels, untreated DU 145 cells, PKP3EGFP expressing cells, and PKP3 knockdown cells (clone shPKP3-1350) in more detail, we compared the cell proliferation rate via BrdU incorporation. For cells overexpressing PKP3 a significant higher proliferation rate was noticed (Figure 9). This observation implies that

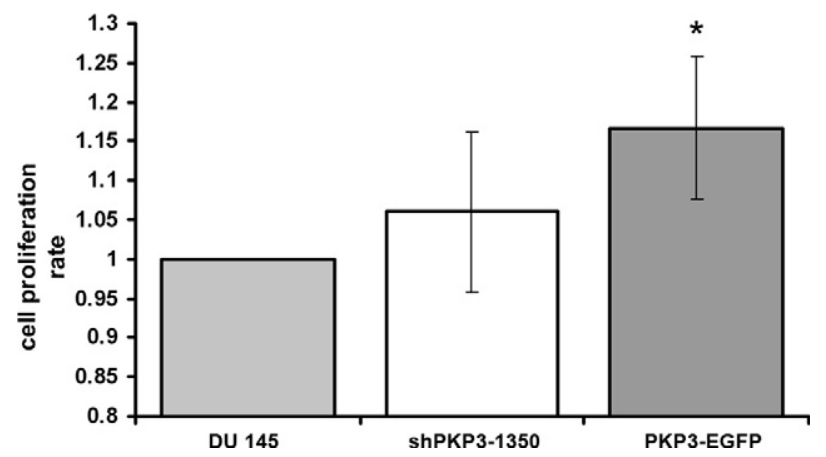

Figure 9. Comparison of the cellular proliferation of untreated DU 145 cells (DU 145) and DU 145 cell lines with knockdown (shPKP3-1350) or overexpression (PKP3-EGFP) of PKP3 as measured by BrdU incorporation. For experimental details, see Materials and Methods. The data represent the mean cumulative values of three independent experiments including SD. The absorbance obtained for DU 145 cells was set as reference point 1.0. A significant difference $\left({ }^{*} P<0.05\right)$ compared with DU 145 cells was observed for PKP3-overexpressing cells as assessed with Student's $t$-test for unpaired experiments.

PKP3 contributes to the regulation of cell growth and cell division.

\section{Discussion}

The present study demonstrates the presence of all three plakophilins, PKP1-3, in luminal and basal cells of the glandular epithelium of the prostate. In prostatic adenocarcinomas, PKP1 expression was decreased with increasing tumor grade, whereas the expression of PKP3 conversely was increased in tumors with high compared with low Gleason scores. PKP2 expression was similar in all tumors, irrespective of Gleason score. Interference with the level of PKP3 expression in a cell culture model influenced the formation of desmosomes and the proliferation rate.

In epithelia, the distribution of plakophilins can be considered as a marker for differentiation. Among the plakophilin family, PKP2 is the most widespread desmosomal plaque protein, occurring in simple, complex, and certain stratified epithelia. ${ }^{5,10}$ Another member less widely distributed is PKP3, which is found in desmosomes of most simple and almost all stratified epithelia and cell lines derived therefrom, with a remarkable exception of hepatocytes. ${ }^{12,13}$ In contrast, PKP1 is the least common plakophilin. It has been reported to occur in stratified epithelia, urothelium, and certain complex epithelia. ${ }^{11,29,30}$ Until recently, any studies on the distribution of plakophilins in the glandular epithelium of the prostate were not available. We show for the first time by immunofluorescence, immunoelectron microscopy, and immunoblot the occurrence of all three plakophilins in luminal and basal cells of pseudostratified prostate epithelium. Similarly, PKP1 has been reported to occur in other glandular epithelia such as, for example, the inner dermal ductal cells in eccrine sweat glands ${ }^{30}$ or the mammary gland ducts. ${ }^{11}$

We analyzed 135 cases of prostatic adenocarcinomas and noticed a generally inhomogeneous expression of PKP1 in adenocarcinomas with intermediate $(69 \%)$ or 
high (70\%) Gleason score. In tumor areas with high Gleason pattern, PKP1 was no longer detectable, whereas the expression of the two other PKPs, PKP2 and PKP3, was either unchanged (PKP2) or even increased (PKP3). One previous study ${ }^{31}$ reported the presence of all three plakophilins in prostate carcinomas but did not address the association with Gleason grading. In other human tumors, the expression of plakophilins seems to differ between different entities. In oropharyngeal tumors, a reduction or an absence of PKP1 and PKP3 in desmosomes has been noticed. ${ }^{17}$ In contrast, non-small cell lung carcinomas were reported to show up-regulation of PKP3. ${ }^{16}$ An inhomogeneous expression of PKP1 in tumors has been described in several reports, ${ }^{18,30,32,33}$ and it has been suggested that PKP1 functions as a differentiation marker for carcinomas. ${ }^{30}$ In glandular epithelium, the detection of PKP1 might be a valuable indicator of well-differentiated glandular structures. Differences in the occurrence of PKPs (eg, loss, up-regulation, or inhomogeneous expression) could reflect tumor progression, as already noticed for protein $\mathrm{p} 120 .{ }^{15}$

By using DU 145 cultured cancer cells as a cell culture model, deduced from a brain metastasis of a prostatic adenocarcinoma, we interfered with the expression level of PKP3. Both the knockdown (loss of function) and the overexpression (gain of function) resulted in formation of fewer desmosomes, and the overexpression led to a higher proliferation rate. The essential importance of all three PKPs has been shown in vitro in cultured cells via knockdown approaches. ${ }^{18,34,35}$ The down-regulation of PKP1 and PKP3 resulted in a decreased formation of desmosomes and increased cell motility and invasion. ${ }^{18,35}$ PKPs do not only contribute to formation and maintenance of desmosomes $^{22,34,36}$ but also function in the cyto- and nucleoplasm. ${ }^{27,37}$ PKP2 has been found in nuclear particles containing RNA polymerase III. ${ }^{37}$ Moreover, cytoplasmic PKP1 and PKP3 are components of RNA-containing particles and can be recruited to stress granules. ${ }^{27}$ The overexpression of PKP3 led to a higher portion of PKP3 in the cytoplasmic pool and thereby may regulate cell growth and cell division and effect the formation of desmosomes. A deficiency in one of the PKPs has a tremendous impact on epithelial integrity in animals and humans. Ablation of PKP1 results in skin fragility and hypohidrotic ectodermal dysplasia. ${ }^{38}$ Knockout PKP2 mice exhibit lethal alterations in heart morphogenesis. ${ }^{39}$ PKP3-deficient mice develop hair coat abnormalities and are prone to cutaneous inflammation. ${ }^{40}$

Clearly, future studies will have to reveal the function of PKP1 and 3 in the cytoplasm and how exchange of the junctional and nonjunctional form is regulated in healthy and diseased states such as, for example, cancer.

\section{Acknowledgments}

We thank Prof. Dr. Werner W. Franke (Helmholtz Group for Cell Biology, German Cancer Research Center) and Prof. Dr. Hellmut G. Augustin (Joint Research Division Vascular Biology of the Medical Faculty Mannheim) for continuous and generous support.

\section{References}

1. Hartsock A, Nelson WJ: Adherens and tight junctions: structure, function and connections to the actin cytoskeleton. Biochim Biophys Acta 2008, 1778:660-669

2. Getsios S, Huen AC, Green KJ: Working out the strength and flexibility of desmosomes. Nat Rev Mol Cell Biol 2004, 5:271-281

3. Hatzfeld M: The p120 family of cell adhesion molecules. Eur Cell Biol 2005, 84:205-214

4. Schmidt A, Jäger S: Plakophilins-hard work in the desmosome recreation in the nucleus? Eur J Cell Biol 2005, 84:189-204

5. Mertens C, Kuhn C, Franke WW: Plakophilins 2a and 2b constitutive proteins of dual location in the karyoplasm and the desmosomal plaque. J Cell Biol 1996, 13:1009-1025

6. Schmidt A, Langbein L, Rode M, Prätzel S, Zimbelmann R, Franke WW: Plakophilins 1a and 1b: widespread nuclear proteins recruited in specific epithelial cells as desmosmal plaque components. Cell Tissue Res 1997, 290:481-499

7. Nelson WJ, Nusse R: Convergence of Wnt, beta-catenin, and cadherin pathways. Science 2004, 303:1483-1487

8. Hofmann I, Kuhn C, Franke WW: Protein p0071, a major plaque protein of non-desmosomal adhering junctions, is a selective cell type marker. Cell Tissue Res 2008, 334:381-399

9. Hofmann I, Schlechter T, Kuhn C, Hergt M, Franke WW: Protein p0071, an armadillo plaque protein that characterizes a specific subtype of adherens junctions. J Cell Sci 2009, 122:21-24

10. Mertens C, Kuhn C, Moll R, Schwetlick I, Franke WW: Desmosomal plakophilin 2 as a differentiation marker in normal and malignant tissues. Differentiation 1999, 64:277-290

11. Heid HW, Schmidt A, Zimbelmann R, Schäfer S, Winter-Simanowski S, Stumpp S, Keith M, Figge U, Schnölzer M, Franke WW: Cell type-specific desmosomal plaque proteins of the plakoglobin family: plakophilin 1 (band 6 protein). Differentiation 1994, 58:113-131

12. Bonné S, van Hengel J, Nollet F, Kools P, van Roy F: Plakophilin-3, a novel armadillo-like protein present in nuclei and desmosomes of epithelial cells. J Cell Sci 1999, 112:2265-2276

13. Schmidt A, Langbein L, Prätzel S, Rode M, Rackwitz H-R, Franke WW: Plakophilin 3-a novel cell-type-specific desmosomal plaque protein. Differentiation 1999, 64:291-306

14. Korinek V, Barker N, Morin PJ, van Wichen D, de Weger R, Kinzler $\mathrm{KW}$, Vogelstein $\mathrm{B}$, Clevers $\mathrm{H}$ : Constitutive transcriptional activation by a $\beta$-catenin-Tcf complex in APC $^{-/-}$colon carcinoma. Science 1997 275:1784-1787

15. van Hengel J, van Roy F: Diverse functions of p120ctn in tumors. Biochem Biophys Acta 2007, 1773:78-88

16. Furukawa C, Daigo Y, Ishikawa N, Kato T, Ito T, Tsuchiya E, Sone S, Nakamura $Y$ : Plakophilin 3 oncogene as prognostic marker and therapeutic target for lung cancer. Cancer Res 2005, 65:7102-7110

17. Papagerakis S, Shabana A-H, Depondt J, Gehanno P, Forest N: Immunohistochemical localization of plakophilins (PKP1. PKP2, PKP3 and p0071) in primary oropharyngeal tumors: correlation with clinical parameters. Hum Pathol 2003, 34:565-572

18. Sobolik-Delmaire T, Katafiasz D, Keim SA, Mahoney MG, Wahl JK III: Decreased plakophilin-1 expression promotes increased motility in head and neck squamous cell carcinoma cells. Cell Commun Adhesion 2007, 14:99-109

19. Hayward SW, Dahiya R, Cunha GR, Bartek J, Deshpande N, Narayan $P$ : Establishment and characterization of an immortalized but nontransformed human prostate epithelial cell line: bPH-1. In Vitro Cell Dev Biol Anim 1995, 31:14-24

20. Epstein JI, Allsbrook WC Jr, Amin MB, Egevad LL, ISUP Grading Committee: The 2005 International Society of Urological Pathology (ISUP) Consensus Conference on Gleason Grading of Prostatic Carcinoma. Am J Surg Pathol 2005, 29:1228-1242

21. Zettl A, Meister S, Katzenberger T, Kalla J, Ott MM, Müller-Hermelink $\mathrm{H}-\mathrm{K}$, Ott G: Immunohistochemical analysis of B cell lymphoma using tissue microarrays identifies particular phenotypic profiles of $\mathrm{B}$ cell lymphomas. Histopathology 2003, 432:209-219

22. Koeser J, Troyanovsky SM, Grund C, Franke WW: De novo formation of desmosomes in cultured cells upon transfection of genes encoding specific desmosomal components. Exp Cell Res 2003, 285:114-130

23. Walter B, Schlechter T, Hergt M, Berger I, Hofmann I: Differential expression pattern of protein ARVCF in nephron segments of human and mouse kidney. Histochem Cell Biol 2008, 130:943-956 
24. Paffenholz R, Kuhn C, Grund C, Stehr S, Franke WW: The arm-repeat protein NPRAP (neurojungin) is a constituent of the plaques of the outer limiting zone in the retina, defining a novel type of adhering junction. Exp Cell Res 1999, 250:452-464

25. Hofmann I, Schnölzer M, Kaufmann I, Franke WW: Symplekin, a constitutive protein of karyo- and cytoplasmic particles involved in mRNA biogenesis in Xenopus laevis oocytes. Mol Biol Cell 2002, 13:1665-1676

26. Peitsch WK, Hofmann I, Prätzel S, Grund C, Kuhn C, Moll I, Langbein L, Franke WW: Drebrin particles: components in the ensemble regulating actin dynamics of lamellipodia and filopodia. Eur J Cell Biol 2001, 80:567-579

27. Hofmann I, Casella M, Schnölzer M, Schlechter T, Spring H, Franke WW: Identification of the junctional plaque protein plakophilin 3 in cytoplasmic particles containing RNA-binding proteins and the recruitment of plakophilins 1 and 3 to stress granules. Mol Biol Cell 2006, 17:1388-1398

28. van Leenders GJLH, Schalken JA: Epithelial cell differentiation in the human prostate epithelium: implications for the pathogenesis and therapy of prostate cancer. Crit Rev Oncol Hematol 2003, 46:S3-S10

29. Kapprell HP, Owaribe K, Franke WW: Identification of a basic protein of $M_{r} 75,000$ as an accessory desmosomal plaque protein in stratified and complex epithelia. J Cell Biol 1988, 106:1679-1691

30. Moll I, Kurzen H, Langbein L, Franke WW: The distribution of the desmosomal protein, Plakophilin 1, in human skin and skin tumors. J Invest Dermatol 1997, 139-146

31. Schwarz J, Ayim A, Schmidt A, Jäger S, Koch S, Baumann R, Dünne AA, Moll R: Differential expression of desmosomal plakophilins in various types of carcinomas: correlation with cell type and differentiation. Hum Pathol 2006, 37:613-622

32. Kurzen H, Münzing I, Hartschuh W: Expression of desmosomal proteins in squamous cell carcinomas of the skin. J Cutan Pathol 2003, 30:621-630
33. Schmidt-Graeff A, Koeninger A, Olschewski M, Haxelmans S, Nitschke R, Bocahton-Piallat M-L, Lifschitz-Mercer B, Gabbiani G, Langbein L, Czernobilsky B: The $\mathrm{Ki} 67^{+}$proliferation index correlates with increased retinol-binding protein- 1 and the coordinated loss of plakophilin-1 and desmoplakin during progression of cervical squamous lesions. Histopathology 2007, 51:87-97

34. Bass-Zubeck AE, Hobbs RP, Amargo EV, Garcia NJ, Hsieh SN, Chen X, Wahl III JK, Denning MF, Green KJ: Plakophilin 2: a critical scaffold for PKC $\alpha$ that regulates intercellular assembly. J Cell Biol 2008, 181:605-613

35. Kundu ST, Gosave P, Khapare N, Patel R, Hosing AS, Maru GB, Ingle A, DeCaprio JA, Dalal SN: Plakophilin 3 downregulation leads to a decrease in cell adhesion and promotes metastasis. Int J Cancer 2008, 123:2303-2314

36. Wahl III JK: A role for plakophilin-1 in the initiation of desmosome assembly. J Cell Biochem 2005, 96:390-403

37. Mertens C, Hofmann I, Wang Z, Teichmann M, Sepehri Chong S, Schnölzer M, Franke WW: Nuclear particles containing RNA polymerase III complexes associated with junctional plaque protein plakophilin 2. Proc Natl Acad Sci USA 2001, 98:7795-7800

38. McGrath JA, Hoeger PH, Christiano AM, McMillan JR, Mellerio JE, Ashton GHS, Dopping-Hepenstal PJC, Lake BD, Leigh IM, Harper JI, Eady RAJ: Skin fragility and hypohidroitic ectodermal dysplasia resulting from ablation of plakophilin 1. Br J Dermatol 1999, 140:297-307

39. Grossmann KS, Grund C, Huelsken J, Behrend M, Erdmann B, Franke WW, Birchmeier W: Requirement of plakophilin 2 for heart morphogenesis and cardiac junction formation. J Cell Biol 2004, 167:149-160

40. Sklyarova T, Bonné S, D’hooge P, Denecker G, Gossens S, De Rycke $R$, Borgonie G, Bösl M, van Roy F, van Hengel J: Plakophilin-3deficient mice develop hair coat abnormalities and are prone to cutaneous inflammation. J Invest Dermatol 2007, 128:1375-1385 